\title{
Effect of key parameters on the removal of formaldehyde and methanol in gas-phase biotrickling filters
}

\author{
Ó.J. Prado, M.C. Veiga, C. Kennes \\ Journal of Hazardous Materials, Volume 138, Issue 3, 1 Dec 2006, Pages 543-548 \\ DOI: 10.1016/j.jhazmat.2006.05.093
}

\begin{abstract}
The effect of some important operation parameters, as $\mathrm{pH}$, pollutant load and composition of the nutrient media, on the biodegradation of a mixture of formaldehyde and methanol in a gas-phase biotrickling filter was studied. $\mathrm{pH}$ proved to affect the degradation of both compounds at moderately acidic values. Replacing ammonium with nitrate as nitrogen source in the liquid solution led to a slight decrease in performance, though this difference was not really significant. A slight decrease in the elimination rate was also observed when reducing the $\mathrm{N}-\mathrm{NO}_{3}{ }^{-}$concentration to $60 \%$ of its original value. No interactions between the two pollutants were found under our working conditions.
\end{abstract}

\section{Keywords}

Bioremediation; Biofilter; Optimization; Synthetic resins; Waste gas

\section{Introduction}

The emission of hazardous compounds to the environment has widely increased over the past decades, mainly as a consequence of the industrial development and the growing consumption of organic fuels. This is one of the most important problems that governments and society will have to face during the present century. Among these substances, methanol and formaldehyde are of special interest, due to their relatively high emission levels and their negative effects on health [1]. Both are major pollutants in waste gases from wood industries. They are among others present in particle board press vents and are also found in exhaust gases from synthetic-resin producing industries, usually in combination with other contaminants [2]. Their concentration do generally not exceed a few hundreds of milligrams per cubic meter, at most. Such compounds, as most other common air pollutants, have traditionally mainly been treated by means of non-biological technologies, such as absorption, adsorption and incineration [3]. These conventional treatment processes are often expensive and do, in some cases, simply transfer the pollutant from one phase (gas) to another (liquid or solid). Therefore, huge efforts have been made recently in order to develope new, efficient technologies that overcome the side-effects associated with classical methods. Biological technologies, which are based on the ability of certain microbial strains to use volatile pollutants as carbon and energy source, have proved to be good alternatives to traditional technologies, due to their relatively low cost, high efficiency and absence 
of generation of hazardous by-products [4]. Bioprocesses, mainly biofiltration, were originally applied to odour treatment at sewage, composting, and rendering works and intensive stock breading [5]. More recently, the application of bioprocesses for air pollution control has been extended to new applications, including industrial waste gas treatment. Besides, new bioreactor configurations have been proposed, including, among others, biotrickling filters, membrane bioreactors, rotating biological contactors, or systems based on combined advanced oxidation and biodegradation processes [3], [6] and [7]. Bioprocesses are now being applied to a much wider range of pollutants than a few decades ago. In some previous studies, bioreactors have been employed for the elimination of gas-phase mixtures of methanol and formaldehyde, with quite good results [1], [2], [8] and [9].

The objective of the work presented here was to optimize the treatment of mixtures of formaldehyde and methanol in gas-phase bioreactors. The effect of some important operation parameters, like pollutant load, composition of the nutrient media and $\mathrm{pH}$, on bioreactor performance has been checked in a biotrickling filter packed with lava rock.

\section{Nomenclature}

\begin{tabular}{|l|l|}
\hline EBRT & empty bed residence time, $t$ (s) \\
\hline FEC & $\begin{array}{l}\text { formaldehyde elimination capacity } \\
\left(\mathrm{ML}^{-3} \mathrm{t}^{-1}\right)\end{array}$ \\
\hline FL & formaldehyde load $\left(\mathrm{ML}^{-3} \mathrm{t}^{-1}\right)$ \\
\hline FRE & formaldehyde removal efficiency \\
\hline MEC & methanol elimination capacity $\left(\mathrm{ML}^{-3} \mathrm{t}^{-1}\right)$ \\
\hline ML & methanol load $\left(\mathrm{ML}^{-3} \mathrm{t}^{-1}\right)$ \\
\hline MRE & methanol removal efficiency \\
\hline VSS & volatile suspended solids $\left(\mathrm{ML}^{-3}\right)$ \\
\hline
\end{tabular}

\section{Materials and methods}

\subsection{Bioreactors}

The biotrickling filters employed during these studies were packed with $2.0 \mathrm{~L}$ lava rock, except in the experiments on the effect of methanol and formaldehyde load on bioreactor performance, in which $1 \mathrm{~L}$ lava rock was used. The main characteristics of the reactors have already been described elsewhere [1]. The systems were operated with a downward flow, at room temperature. An aerobic sludge obtained from the wastewater treatment plant of a synthetic resin-producing industry was used as inoculum [2]. The bioreactors were continuously fed a nutrient solution described elsewhere [10], which was recirculated at a rate of $3 \mathrm{~L} / \mathrm{h}$ and periodically renewed, unless otherwise indicated. That solution was periodically analyzed to check that neither methanol nor formaldehyde were being dissolved in the liquid phase instead of being biodegraded. The results showed that less than 3\% formaldehyde and methanol was lost in the liquid phase. 


\subsection{Batch experiments}

All the batch assays were performed in $635 \mathrm{~mL}$-vials, containing $100 \mathrm{~mL}$ sludge (previously diluted to achieve a biomass concentration of $3.5 \mathrm{~g} \mathrm{VSS} / \mathrm{L}$ ), with the same nutrient solution as for the bioreactor studies [10]. The final total volume was $150 \mathrm{~mL}$. After adding the pollutant, the vials were sealed and maintained at $30{ }^{\circ} \mathrm{C}$ with constant shaking at $200 \mathrm{rpm}$. Samples of the pollutant were taken periodically. All the vials were prepared in duplicate, including "blanks" and "controls". The "blanks" were identical to the experimental vials with the highest pollutant concentration, but had been sterillized. "Control" vials had also that same composition, but contained distilled water instead of sludge.

\subsection{Analytical methods}

Gas-phase pollutant concentrations were measured by means of a HP-6890 gas chromatograph equipped with a $30 \mathrm{~m} \times 0.53 \mathrm{~mm}$ HP-PLOT Q column and a flame ionization detector, operating in splitless mode. Oven temperature was $130^{\circ} \mathrm{C}$, while both the injector and the detector were at $150{ }^{\circ} \mathrm{C}$. Samples were injected using a $2.5 \mathrm{~cm}^{3}$ gas-tight Hamilton syringe. Under these conditions, the retention times of formaldehyde and methanol were, respectively, 2.4 and $3.5 \mathrm{~min}$. Calibrations were performed as described previously [11]. Samples of the liquid solution supplied to the reactors were periodically tested for $\mathrm{pH}$, which was measured by means of an Ingold U455-S7 electrode connected to a Crison pH-meter 507. A Warburg manometer was used to measure the pressure drop. Formaldehyde concentration in the liquid phase was measured spectrophotometrically, according to the method of Nash [12]. For methanol determination in the liquid phase a HP-5890-II GC was used, with a $30 \mathrm{~m} \times 0.25 \mathrm{~mm}$ Innowax column. Injector and detector temperatures were set at 250 and $270{ }^{\circ} \mathrm{C}$, respectively. Initial oven temperature was set at $90^{\circ} \mathrm{C}$, with an immediate increase of $3^{\circ} \mathrm{C} / \mathrm{min}$, up to $100{ }^{\circ} \mathrm{C}$.

\section{Results and discussion}

\subsection{Effect of the $\mathrm{pH}$ on the treatment}

The results obtained in a previous study [1] suggest that the efficiency of the treatment of mixtures of methanol and formaldehyde in bioreactors may be partially inhibited at $\mathrm{pH}$ values below ca. 4.2. It is well known that for many bacteria low $\mathrm{pH}$ values may affect biodegradation rates to a great extent, although acidophilic bacteria and fungi may tolerate relatively low $\mathrm{pH}$ values and degrade VOCs in acidic environments [13] and [14]. In the present experiment, the effect of $\mathrm{pH}$ on the biodegradation of volatile organic compounds was checked both in batch studies and in a biotrickling filter as described hereafter.

\subsubsection{Batch studies}

The effect of $\mathrm{pH}$ on methanol biodegradation was studied first. Three different groups of vials were prepared, with the $\mathrm{pH}$ buffered at 4.0, 5.5 and 7.5 , respectively. A concentration of $350 \mathrm{~g}$ methanol $/ \mathrm{m}^{3}$ liquid was added to each vial. Gas samples were collected from the headspace of the vials to measure the methanol concentration. The concentration in the liquid phase was calculated by means of Henry's law. The results 
show that the treatment was strongly affected by the $\mathrm{pH}$ of the medium (Fig. 1). In the vials at $\mathrm{pH} 7.5$ the biodegradation was completed in $6 \mathrm{~h}$, while complete removal took more than $30 \mathrm{~h}$ at the lowest $\mathrm{pH}$. No methanol elimination was observed in the blank and control vials.

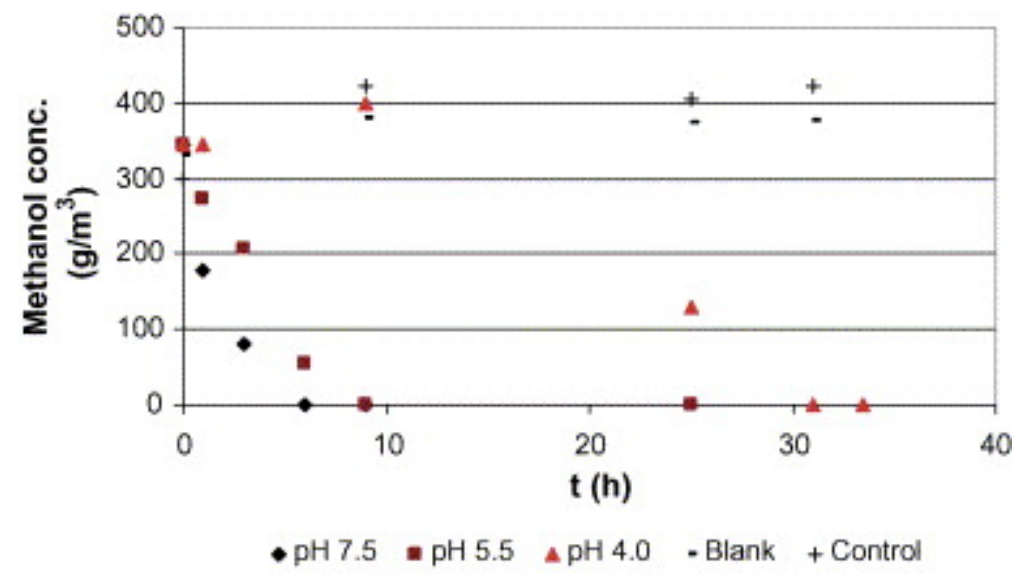

Fig. 1.

Effect of pH on methanol elimination in batch studies.

Subsequently, the effect of $\mathrm{pH}$ on formaldehyde elimination was studied. Again, three groups of vials were prepared, with media buffered at $\mathrm{pH}$ 4.0, 5.5 and 7.5, respectively. A concentration of $200 \mathrm{~g}$ formaldehyde $/ \mathrm{m}^{3}$ liquid was added to each vial. As in the previous case, the results show that formaldehyde elimination is significantly faster at $\mathrm{pH} 7.5$ and that the biodegradation rate gradually decreases when lowering the $\mathrm{pH}$ (Fig. 2). Again, no significant elimination was observed in the blank and control vials.

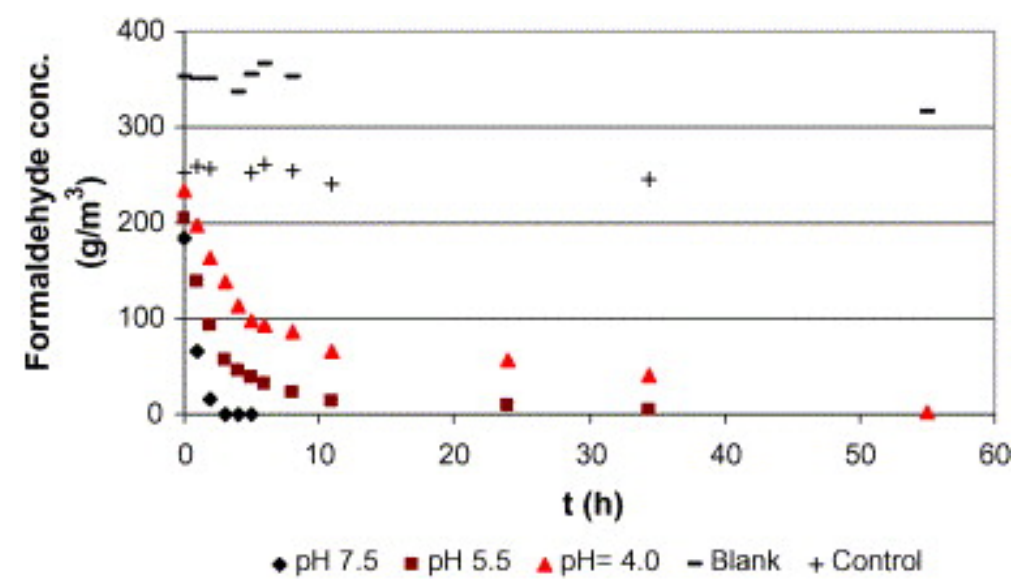

Fig. 2.

Effect of $\mathrm{pH}$ on formaldehyde elimination in batch studies.

\subsubsection{Biotrickling filter}

In a subsequent experiment, the performance of a formaldehyde-degrading biotrickling filter was checked at different $\mathrm{pH}$ values during a total period of more than 2 months. No methanol was fed in the present experiment. The formaldehyde load was set at $42.6 \pm 6.8 \mathrm{~g} / \mathrm{m}^{3} \mathrm{~h}$, and the $\mathrm{pH}$ of the recirculating solution varied between 3.9 and 6.5 
during that period. The rest of the operation parameters were kept constant during the experiment. The recirculation rate was set at $3 \mathrm{~L} / \mathrm{h}$. Fig. 3 shows that the performance of the biotrickling filter was not affected by a slightly acidic $\mathrm{pH}$, but that it started decreasing at values below ca. 4.5. This is consistent with the results of the batch assays and with preliminary data on the effect of acidification in bioreactor experiments [1].

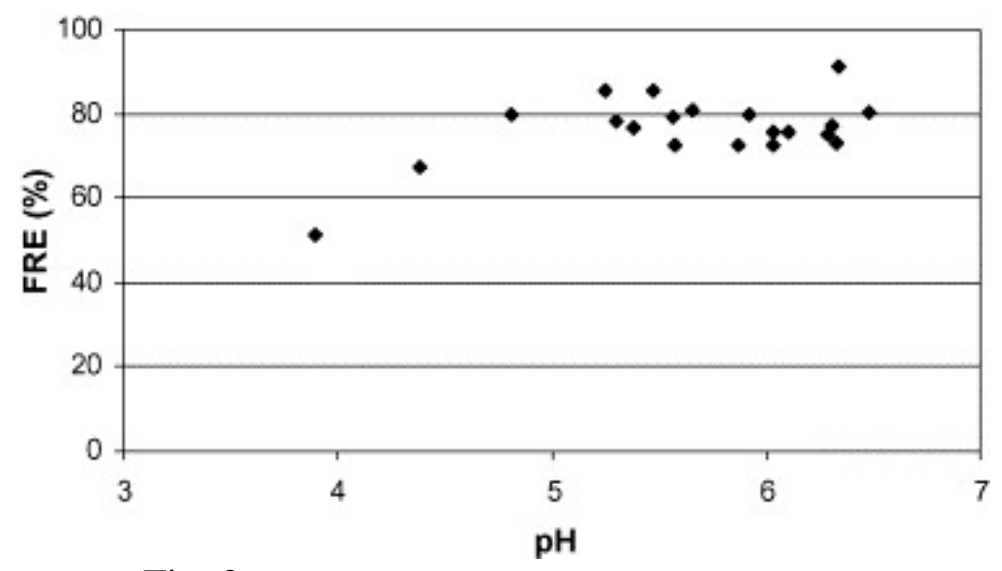

Fig. 3.

Effect of $\mathrm{pH}$ on the formaldehyde removal efficiency of a biotrickling filter operated for more than 2 months.

\subsection{Effect of the nitrogen supply}

One of the problems that are usually observed in the biotreatment of volatile organic compounds is the $\mathrm{pH}$ drop of the medium, as a consequence of the generation of acidic metabolites. This decrease may be rather intense if ammonium is used as nitrogen source. A few potential solutions to this problem have been proposed, such as the development of acid-tolerant fungi [5], [14] and [15] or the use of alternative nitrogen sources. So far, nitrogen sources employed in bioreactors besides ammonium are nitrate [16], urea [17] and organic nitrogen, typical from natural organic packing materials [18]. Among them, nitrate is most commonly used, though, for many microorganisms, its uptake is more difficult than for ammonium.

The present experiment, which lasted 245 days, was divided in three stages. The biotrickling filter used was the same as in the previous case, but different solutions of macronutrients were used for feeding the bioreactor. Solution A contained ammonia as nitrogen source, while solutions $\mathrm{B}$ and $\mathrm{C}$ contained nitrate in different concentrations (Table 1). Moreover, the performance of the reactor was checked in each stage at two different EBRT values (47 and 70 s). The rest of the operation parameters were kept constant. 
Table 1.

Composition of the macronutrient solutions (concentrations in $\mathrm{g} / \mathrm{L}$ )

\begin{tabular}{|c|c|c|c|}
\hline & \multicolumn{3}{|c|}{ Solution } \\
\hline & $A$ & B & C \\
\hline $\mathrm{MgSO}_{4} \cdot 7 \mathrm{H}_{2} \mathrm{O}$ & 0.12 & 0.12 & 0.12 \\
\hline $\mathrm{KH}_{2} \mathrm{PO}_{4}$ & 0.25 & 0.25 & 0.25 \\
\hline$\left(\mathrm{NH}_{4}\right)_{2} \mathrm{SO}_{4}$ & 1.18 & - & - \\
\hline $\mathrm{NaCl}$ & 1.00 & 1.00 & 1.00 \\
\hline $\mathrm{NH}_{4} \mathrm{Cl}$ & 0.96 & - & - \\
\hline $\mathrm{KNO}_{3}$ & $E$ & 3.62 & 2.20 \\
\hline $\mathrm{N}$ & 0.50 & 0.50 & 0.30 \\
\hline
\end{tabular}

The bioreactor was operated during more than 60 days with $2 \mathrm{~L}$ of each solution, at a recirculation rate of $3.0 \mathrm{~L} / \mathrm{h}$. The nutrient solution was renewed once a week, with the $\mathrm{pH}$ adjusted to 7.5 , although a gradual acidification was observed. The inlet formaldehyde concentrations were $0.8 \pm 0.3,0.9 \pm 0.2$ and $0.8 \pm 0.2 \mathrm{~g} / \mathrm{m}^{3}$, when using solutions A, B and C, respectively. The results show that the average performance of the reactor was similar with the three solutions (Table 2). A small decrease in the removal efficiency was observed when replacing solution $A$ by solution $B$, though this difference is not really significant. The $\mathrm{pH}$ of the medium was $5.5 \pm 1.1$ when feeding solution $\mathrm{A}$, containing ammonium, while with solution $\mathrm{B}$, containing nitrate, it was $6.0 \pm 0.4$. A maximum formaldehyde elimination capacity of $101 \mathrm{~g} / \mathrm{m}^{3} \mathrm{~h}$ was obtained in this experiment, when feeding solution A.

Table 2.

Effect of the nitrogen source on bioreactor operation

\begin{tabular}{|c|c|c|c|c|}
\hline Solution & EBRT (s) & FL $\left(g / \mathrm{m}^{3} h\right)$ & FEC $\left(\mathrm{g} / \mathrm{m}^{3} \mathrm{~h}\right)$ & FRE (\%) \\
\hline \multirow{2}{*}{ A } & 71.9 & $46.2 \pm 14.1$ & $41.2 \pm 15.8$ & $87.2 \pm 8.8$ \\
\hline & 46.5 & $72.6 \pm 9.1$ & $68.0 \pm 9.4$ & $93.5 \pm 1.5$ \\
\hline \multirow[b]{2}{*}{ B } & 72.0 & $46.4 \pm 7.3$ & $37.1 \pm 5.8$ & 80.1 \\
\hline & 48.3 & $71.8 \pm 10.6$ & $58.2 \pm 8.1$ & $81.0 \pm 1.8$ \\
\hline \multirow[b]{2}{*}{ U } & 69.2 & $46.4 \pm 4.7$ & $35.9 \pm 2.4$ & $77.6 \pm 3.5$ \\
\hline & 47.7 & $74.6 \pm 25.8$ & $57.4 \pm 22.9$ & $75.9 \pm 7.3$ \\
\hline
\end{tabular}

Average value \pm standard deviation.

A number of studies have suggested that ammonium is a more accesible nitrogen source than nitrate for microorganisms. Jorio et al. [19] employed both compounds as nitrogen source in two styrene-degrading conventional biofilters. The reactor fed ammonium reached an elimination capacity significantly higher than when feeding nitrate (141 
against $50 \mathrm{~g} / \mathrm{m}^{3} \mathrm{~h}$ ). However, excessive biomass growth was observed in the first one. In our experiment a low pressure drop, always below $4 \mathrm{~mm}$ water/m filter bed was observed, indicating that the biomass had not grown in excess, thus avoiding clogging problems. Some other studies suggest that nitrate as nitrogen source can give better results in bioreactors. In two toluene-degrading biotrickling filters fed, respectively, with ammonium- and nitrate-containing solutions, it was showed that the latter could eliminate up to $70 \%$ more COD for a given mass of nitrogen, generating $40 \%$ less VSS than with ammonium for the same amount of COD degraded [16]. According to this work, the higher amount of energy available in the bioreactor fed ammonium allowed the development of a wide community of microorganisms unable to degrade toluene.

In the third stage of our experiment, the bioreactor was fed solution $\mathrm{C}$ with a nitrogen concentration $40 \%$ lower that in solution B. Only a small decrease in removal efficiency, around 4\%, was found when comparing the results obtained in the two last stages (Table 2). The relationship between nitrogen concentration and bioreactor performance has been shown in different studies [17], [18], [20], [21] and [22]. Fig. 4 shows the influence of the formaldehyde load on its elimination capacity in the three stages, with both EBRT. The highest weekly carbon load during this study was $9.7 \mathrm{~g} \mathrm{C} /$ week, considering that the filter bed volume was $2 \mathrm{~L}$ and that the average $\mathrm{FL}$ was around $72 \mathrm{~g} / \mathrm{m}^{3} \mathrm{~h}$. Since the $2 \mathrm{~L}$ nutrient solution was renewed weekly, the (C:N) ratio appeared to be $(9.7: 1)$ for the solutions containing $0.50 \mathrm{~g} \mathrm{~N} / \mathrm{L}$ and (16.1:1) when supplying $0.30 \mathrm{~g} \mathrm{~N} / \mathrm{L}$. 


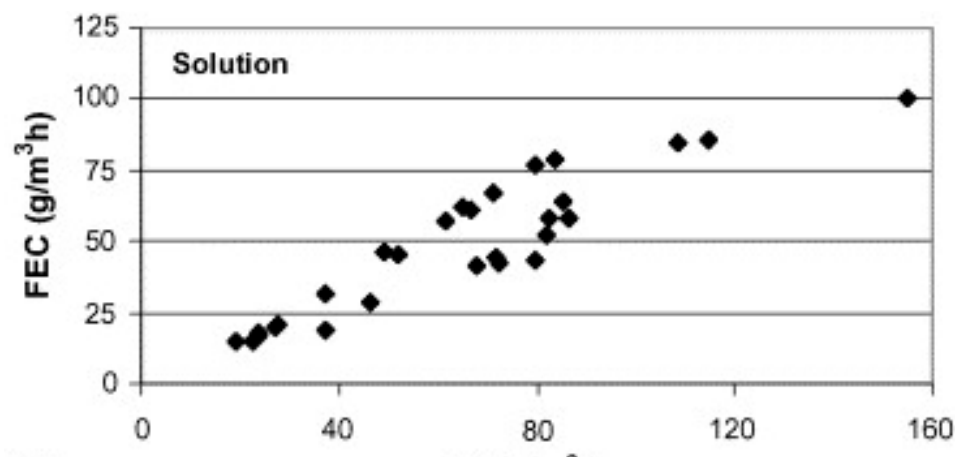

(A)

FL $\left(g / m^{3} h\right)$

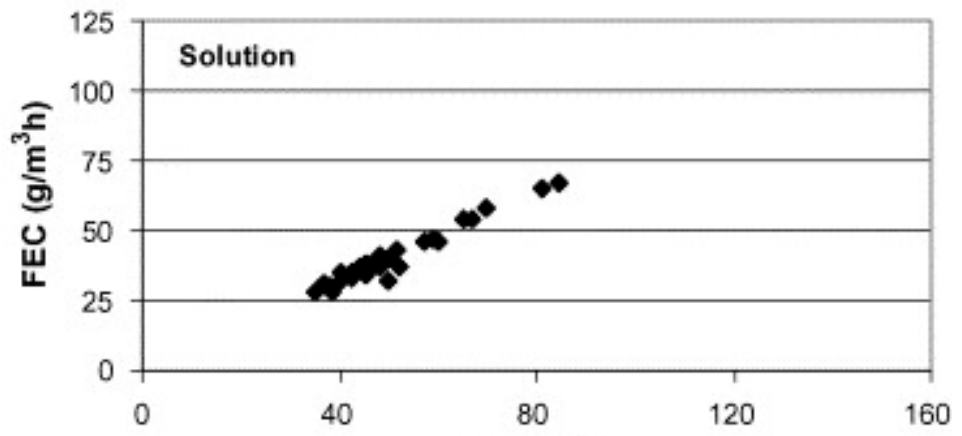

(B)

$\mathrm{FL}\left(\mathrm{g} / \mathrm{m}^{3} \mathrm{~h}\right)$

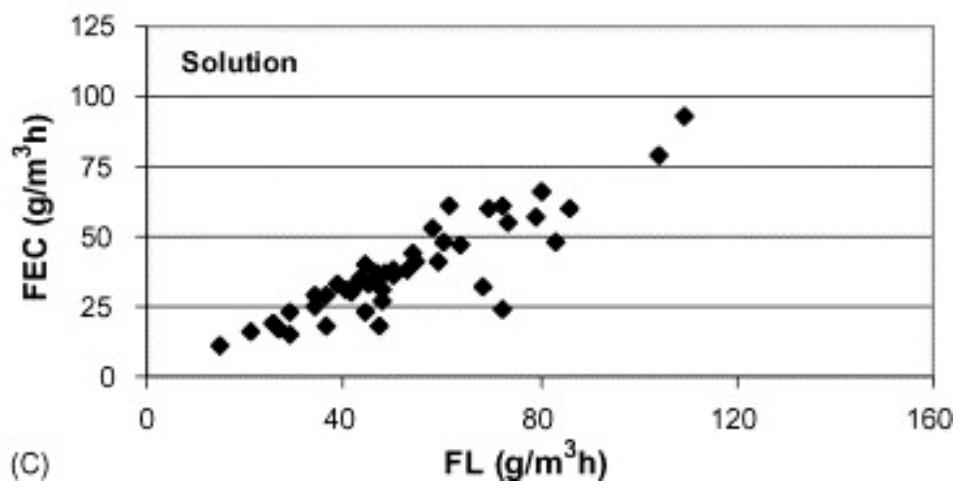

Fig. 4.

Formaldehyde load vs. elimination capacity in the three experimental stages.

\subsection{Effect of the methanol load on the elimination of the mixture}

A trickling biofilter fed continuously with $3.0 \mathrm{~L} / \mathrm{h}$ of solution $\mathrm{C}$ was operated during more than 4 months, in which methanol loads ranging from 40 to $660 \mathrm{~g} / \mathrm{m}^{3} \mathrm{~h}$ and a constant formaldehyde load of $50 \mathrm{~g} / \mathrm{m}^{3} \mathrm{~h}$ were simultaneously fed to the reactor. This reactor, which had been treating mixtures of formaldehyde and methanol for around 8 months uninterruptedly, had a filter bed volume of $1.0 \mathrm{~L}$, and the EBRT was set at $36 \mathrm{~s}$. The rest of the operation parameters were the same as in the previous experiment. The results presented in Fig. 5 show that there is apparently no effect of the methanol load on the formaldehyde elimination under these conditions, even at high methanol loads around $600 \mathrm{~g} / \mathrm{m}^{3} \mathrm{~h}$. Conversely, it was previously observed that if such high loads are applied during the start-up phase, only a few days after inoculation, a clear inhibition of formaldehyde removal is detected [1]. Methanol elimination capacity, which reached a 
maximum value of $552 \mathrm{~g} / \mathrm{m}^{3} \mathrm{~h}$, was not affected either. This value is significantly higher that those achieved in a previous experiment carried out in a methanol-degrading biofilter, which showed that methanol elimination capacities around $300 \mathrm{~g} / \mathrm{m}^{3} \mathrm{~h}$ can be reached in conventional biofilters [23]. The results presented here show that the treatment is improved in biotrickling filters.

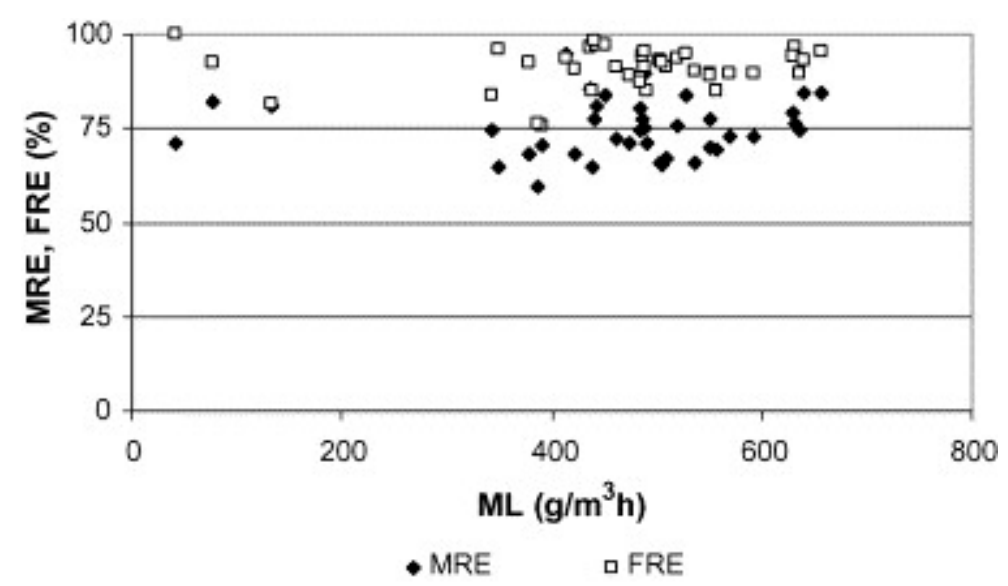

Fig. 5.

Effect of the methanol load on formaldehyde and methanol elimination, when supplying a constant formaldehyde load of $50 \mathrm{~g} / \mathrm{m}^{3} \mathrm{~h}$.

\subsection{Effect of the formaldehyde load on the elimination of the mixture}

In this experiment, analogous to the previous one, the effect of the formaldehyde load on the performance of a biotrickling filter used for the treatment of a mixture of formaldehyde and methanol was studied. The bioreactor employed was the same as in the previous experiment. A constant methanol load of $700 \mathrm{~g} / \mathrm{m}^{3} \mathrm{~h}$ and formaldehyde loads ranging from 30 to $90 \mathrm{~g} / \mathrm{m}^{3} \mathrm{~h}$ were fed to the reactor. The results presented in Fig. 6 show that the increase in the formaldehyde load did not have a significant effect on methanol removal. In fact, some increase in the removal efficiency of formaldehyde was observed when increasing the formaldehyde load.

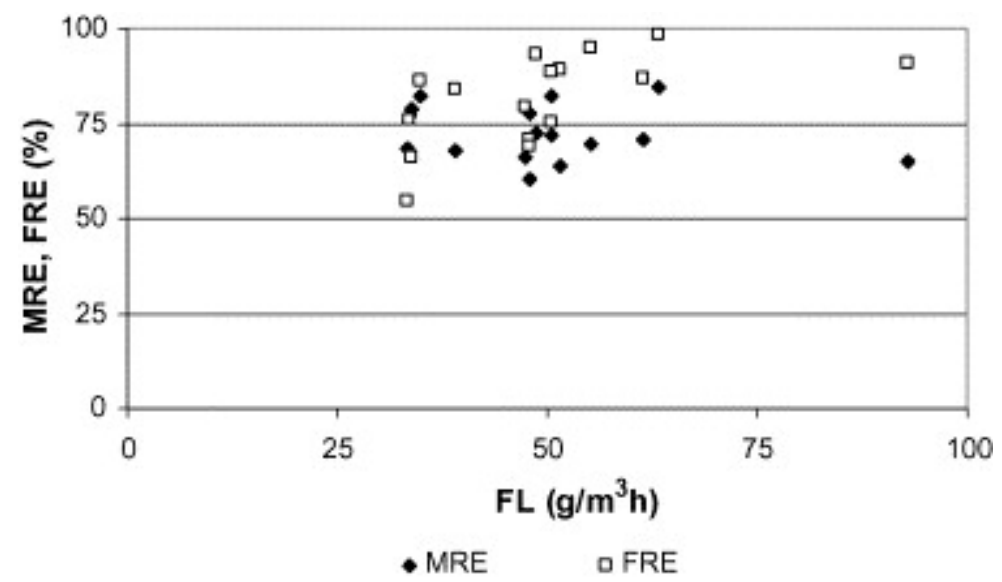

Fig. 6.

Effect of the formaldehyde load on formaldehyde and methanol elimination, when supplying a constant methanol load of $700 \mathrm{~g} / \mathrm{m}^{3} \mathrm{~h}$. 


\section{Conclusions}

The results presented in this study show that the elimination of mixtures of formaldehyde and methanol can be performed in biotrickling filters packed with lava rock with very high efficiencies. In the present study, maximum elimination capacities of 101 and $552 \mathrm{~g} / \mathrm{m}^{3} \mathrm{~h}$ were reached for formaldehyde and methanol, respectively. Batch studies proved that the $\mathrm{pH}$ of the medium has a great influence on the microbial activity, affecting the elimination rate of both compounds. Also, an experiment undertaken in a biotrickling filter showed that the elimination rate of formaldehyde decreased gradually at $\mathrm{pH}$ values below ca. 4.5. Hence, if stable long-term operation is desired, special attention should be given to $\mathrm{pH}$. Optimal $\mathrm{pH}$ values can be maintained by buffering the liquid medium or the filter bed.

Another key parameter in the performance of biotrickling filters is the composition of the liquid solution supplied. In our case, an ammonium-containing medium was continuously recycled at a rate of $3.0 \mathrm{~L} / \mathrm{h}$. Replacing ammonium in the medium with an equivalent amount of nitrate led to a small decrease in the elimination rate of the bioreactor. Subsequently, lowering the $\mathrm{N}-\mathrm{NO}_{3}{ }^{-}$concentration to a value of $60 \%$ of the original one also led to an almost negligible decrease in the removal efficiency, showing that the nitrogen concentration in the nutrient solution was higher than the minimum required for optimal performance. This resulted in a $(\mathrm{C}: \mathrm{N})$ ratio of $(16.1: 1)$. In none of the cases the difference was significant.

The last experiments were aimed at determining the effect of the load of each pollutant on the degradation of the mixture. No interactions between the pollutants were found.

\section{Acknowledgements}

The present research was funded through projects PPQ 2001-0557 and PR404E 2000/60 . The doctoral research of ÓJP was financed by the Xunta de Galicia, Spain.

\section{References}

Ó.J. Prado, M.C. Veiga, C. Kennes

Biofiltration of waste gases containing a mixture of formaldehyde and methanol

Appl. Microbiol. Biotechnol., 65 (2004), pp. 235-242

Ó.J. Prado, M. Eiroa, M.C. Veiga, C. Kennes

Bioreactors for the treatment of industrial waste gases containing formaldehyde and other aliphatic compounds

S.N. Agathos, W. Reineke (Eds.), Focus on Biotechnology, vol. 3C. Biotechnology for the Environment: Wastewater Treatment and Modeling, Waste Gas Handling, Kluwer Academic Publishers, Dordrecht, The Netherlands (2003), pp. 259-273

C. Kennes, M.C. Veiga

Bioreactors for Waste Gas Treatment

Kluwer Academic Publishers, Dordrecht, The Netherlands (2001) 
C. Kennes, F. Thalasso

Waste gas biotreatment technology

J. Chem. Technol. Biotechnol., 72 (1998), pp. 303-319

J.W. van Groenestijn

Biotechniques for air pollution control

C. Kennes, M.C. Veiga (Eds.), Biotechniques for Air Pollution Control (Congress

Proceedings), University of La Coruña Publisher, La Coruña, Spain (2005), pp. 3-12

M.W. Rey, J.T.F. Keurentjes, S. Hartmans

Membrane bioreactors for waste gas treatment

J. Biotechnol., 59 (1998), pp. 155-167

I. Vinage, P. Rudolf von Rohr

Biological waste gas treatment with a modified rotating biological contactor. I. Control of biofilm growth and long-term performance

Bioproc. Biosyst. Eng., 26 (2003), pp. 69-74

H. Tautz, C. Rutenfranz

Biologischer Abbau toxischer Substanzen-Verfahrensauswahl und Betriebserfahrungen mit einer Biowäscher-Pilotanlage

Chem. Eng. Tech., 64 (1992), pp. 192-194

N.V. Doronina, V.A. Ezhov, Y.A. Trotsenko

Aerobic biodegradation of formaldehyde, methanol and methylamine by immobilized Methylobacterium extorquens cells

Appl. Biochem. Microbiol., 33 (1996), pp. 138-141

E. Estévez, M.C. Veiga, C. Kennes

Biodegradation of toluene by the new fungal isolates Paecilomyces variotii and Exophiala oligosperma

J. Ind. Microbiol. Biotechnol., 32 (2005), pp. 33-37

Ó.J. Prado, J.A. Mendoza, M.C. Veiga, C. Kennes

Optimization of nutrient supply in a downflow gas-phase biofilter packed with an inert carrier

Appl. Microbiol. Biotechnol., 59 (2002), pp. 567-573

T. Nash

The colorimetric estimation of formaldehyde by means of the Hantzch reaction

Biochem. J., 55 (1953), pp. 416-421

M.C. Veiga, M. Fraga, L. Amor, C. Kennes

Biofilter performance and characterization of a biocatalyst degrading alkylbenzene gases

Biodegradation, 10 (1999), pp. 169-176

C. Kennes, M.C. Veiga

Fungal biocatalysts in the biofiltration of VOC-polluted air

J. Biotechnol., 113 (2004), pp. 305-319 
J.W. van Groenestijn, W.N.M. van Heiningen, N.J.R. Kraakman

Biofilters based on the action of fungi

Water Sci. Technol., 44 (2001), pp. 227-232

F.L. Smith, G.A. Sorial, M.T. Suidan, A.W. Breen, P. Biswas, R.C. Brenner

Development of two biomass control strategies for extended, stable operation of highly efficient biofilters with high toluene loadings

Environ. Sci. Technol., 30 (1996), pp. 1744-1751

M.C. Delhoménie, L. Bibeau, S. Roy, R. Brzezinski, M. Heitz

Influence of nitrogen on the degradation of toluene in a compost-based biofilter

J. Chem. Technol. Biotechnol., 76 (2001), pp. 997-1006

W.M. Moe, R.L. Irvine

Effect of nitrogen limitation on performance of toluene degrading biofilters

Water Res., 35 (2001), pp. 1407-1414

H. Jorio, L. Bibeau, M. Heitz

Biofiltration of air contaminated by styrene: effect of nitrogen supply, gas flow rate, and inlet concentration

Environ. Sci. Technol., 34 (2000), pp. 1764-1771

X. Zhu, M.T. Suidan, C. Alonso, T. Yu, B.J. Kim, B.R. Kim

Biofilm structure and mass transfer in a gas phase trickle-bed biofilter

Water Sci. Technol., 43 (2001), pp. 285-293

J.H. Song, J. Ramirez, K.A. Kinney

Nitrogen utilization in a vapor-phase biofilter

Water Res., 37 (2003), pp. 4497-4505

H. Yang, B. Minuth, D.G. Allen

Effects of nitrogen and oxygen on biofilter performance

J. Air Waste Manage. Assoc., 52 (2002), pp. 279-286

Ó.J. Prado, M.C. Veiga, C. Kennes

Treatment of gas-phase methanol in conventional biofilters packed with lava rock

Water Res., 39 (2005), pp. 2385-2393 